Research Article

\title{
Aerodynamic Noise Separation of an EMU Trailer Bogie Area Using Train Operation Tests
}

\author{
Leiming Song $\mathbb{D},{ }^{1}$ Hao Chen $\mathbb{D}^{1},{ }^{1}$ and Baochuan $\mathrm{Li}^{2}$ \\ ${ }^{1}$ School of Mechanical and Electronic Control Engineering, Beijing Jiaotong University, Beijing 100044, China \\ ${ }^{2}$ CRRC TANGSHAN CO., LTD., Tangshan, Hebei 064000, China \\ Correspondence should be addressed to Leiming Song; lmsong@bjtu.edu.cn and Hao Chen; 16121313@bjtu.edu.cn
}

Received 27 June 2018; Revised 3 October 2018; Accepted 19 November 2018; Published 2 December 2018

Academic Editor: Francesco Franco

Copyright (c) 2018 Leiming Song et al. This is an open access article distributed under the Creative Commons Attribution License, which permits unrestricted use, distribution, and reproduction in any medium, provided the original work is properly cited.

\begin{abstract}
The operation transfer path analysis (OTPA) technique was used to measure the vibration and noise transfer coefficient functions of wheel-rail noise and radiated noise from an electric multiple unit (EMU) train (high-speed train in China) trailer bogie structure to the central area of the trailer bogie for a train running at speeds of $0-5 \mathrm{~km} / \mathrm{h}$. By applying these transfer coefficient functions to the noise analysis of high-speed train operation, the contributions of wheel-rail noise and frame-radiated noise to the noise of the bogie area at high speeds are obtained, and the aerodynamic noise is separated from the total noise, providing a reference for vibration damping and noise reduction in high-speed trains. Analysis of test data shows that, in the central area of the trailer bogie of high-speed trains, the low-frequency noise mainly comes from the structural radiated noise of the bogie, and the mid- to high-frequency noise is primarily due to aerodynamic noise. In addition, when an EMU train operates at speeds below $250 \mathrm{~km} / \mathrm{h}$, the noise in the central area of the trailer bogie is primarily caused by the structural radiated noise. When the operating speed is higher than $250 \mathrm{~km} / \mathrm{h}$, the noise in the central area of the trailer bogie is mainly due to aerodynamic noise, and the aerodynamic noise contribution increases with increase in speed.
\end{abstract}

\section{Introduction}

The bogie is one of the most important components of an EMU train. The noise of the bogie area directly affects the interior noise of the EMU train and affects the comfort of the train. The noise of an EMU bogie varies with the increase in the running speed of the train. At low speeds, noise is mainly generated from the vibration of the mechanical structure such as rails, wheels, bogies, gear boxes, and motors. At high speeds, noise mainly consists of the aerodynamic noise caused by the air disturbances due to changes in air pressure. This article studies the contribution of aerodynamic noise to the central area of the trailer bogie at high speeds.

Several scholars have studied the aerodynamic noise of high-speed train. Experimental and numerical methods for studying aerodynamic noise are reviewed including the use of microphone arrays, wind tunnels, computational fluid dynamics, and semiempirical methods [1]. Latorre Iglesias et al. developed a semiempirical component-based method for fast prediction of aerodynamic noise from a high-speed train pantograph on the basis of similar models applied to landing gear noise prediction [2]. Zhang et al. analysed the near-field unsteady flow around a pantograph using a largeeddy simulation (LES) with high-order finite difference schemes, using a computational fluid dynamics (CFD)/ Ffowcs Williams-Hawkings (FW-H) acoustic analogy to predict the far-field aerodynamic noise from a pantograph [3]. Gao et al. established a testing method of aerodynamic noise for $1: 8$ scale high-speed train model in an aeroacoustic wind tunnel and the treatment way to highlight the different noise sources of the model. The characteristics of the major noise sources and their contribution to the model were analysed according to the measurement results from the microphones and microphone array out of the flow field [4]. Han et al. conducted a long-term monitoring and analysis of the wheel wear status and the interior vibration-noise of 
coaches $\mathrm{X}$ and $\mathrm{Y}$ marshalled in trains focusing the relationship between the interior abnormal noise and the noncircular wear of wheels [5]. Sun et al. applied detached eddy simulation (DES) to conducting numerical simulations of flow fields around pantographs of high-speed trains which run in the open air [6]. Zhu et al. conducted research on the aerodynamic noise via a simplified model of a high-speed train bogie [7-10]. Nobuhiro et al. studied the aerodynamic noise of high-speed train bogies by using wind tunnels $[11,12]$. Zhu et al. studied the flow simulation and forecasted the aerodynamic noise of a high-speed train wheel set by using a scaling model [13]. Huang et al. performed numerical simulations of the aerodynamic noise of a highspeed train bogie [14]. Zhang et al. studied aerodynamic noise of trailer and motor bogies by using the numerical simulation method and found that the aerodynamic noise in the far field of the trailer bogie was broadband noise, with noise directivity, attenuation, and amplitude characteristics. The main energy was concentrated in the frequency range of $28-56 \mathrm{kHz}[15,16]$. Morita et al., studied the aerodynamic noise sources around the bogie section of a high-speed train and carried out a numerical analysis on them [17]. Frémion et al. studied the aerodynamic noise radiated by a bogie and the intercoach spacing of a high-speed train [18].

This paper presents a method to separate the structural noise and aerodynamic noise in the bogie area of the EMU trailer, which enables the contribution of aerodynamic noise to the bogie area noise to be evaluated. When an EMU train runs at low speed, the noise in the bogie area of the trailer is mainly composed of the noise of the wheel and rail and radiated noise from the bogie frame; the aerodynamic noise is negligible. Therefore, by performing an OTPA method on the test data at low speeds, the transfer coefficient function between the wheel-rail noise and the response point noise in the bogie area, the vibration of the bogie structure, and the response point noise in the bogie area can be obtained. During high-speed operation, the noise in the bogie area includes both structural noise and aerodynamic noise. The air flow in the bogie area is complex, and the installation position and number of acoustic sensors to test the aerodynamic noise source are not easily determined. It is difficult to determine the contribution of the aerodynamic noise to the response point by directly using the OTPA method. Since the transfer coefficient function obtained by the lowspeed operation of the train does not vary with the running speed of the train, it can be used at high speeds to obtain the structural radiant noise during high-speed operation of the train. The contribution of the aerodynamic noise in the bogie area to the response point can be determined by comparing this value to the total value of the target response point obtained by the test.

The test data of the EMU at low speeds are used to obtain the transfer coefficient function, which is then applied to high speeds to extract the aerodynamic noise in the bogie area. Unlike numerical simulation analysis and wind tunnel tests, this method is based on the actual vehicle's line operating conditions, OTPA method, and sound pressure level superposition theory for aerodynamic noise separation research. Only actual measured data under operating conditions need to be obtained to determine the contribution of the aerodynamic noise to the target response point in the bogie area.

\section{Aerodynamic Noise Separation Principle}

2.1. Solving the Structural Noise Contribution Based on the OTPA Method [19]. The transfer coefficient function of each path is solved according to the data of each excitation source and response source under actual measured operating conditions by using the OTPA method. The main contribution of each path is determined by a transfer coefficient function solved and combined with singular value decomposition (SVD) and principal component analysis (PCA) to reduce the deviation caused by the interference between each excitation source and other interference noises.

When the train runs at low speeds, the relationship between excitation source signal and target response point signal under operating conditions is as shown in the following equation:

$$
P=\sum_{i} h_{i} \cdot x_{\mathrm{opi}}
$$

where $P$ represents the target point signal, $h_{i}$ represents the transfer coefficient of the $i$ th excitation point to the target point, and $x_{\text {opi }}$ represents the ith excitation point signal under operating conditions.

SVD refers to any real matrix $X \in R_{m \times n}$. There must be an orthogonal matrix $U \in R_{m \times m}, V \in R_{n \times n}$, and a diagonal matrix $D \in R_{m \times n}$ that satisfies the following equation:

$$
X=U D V^{\mathrm{T}}
$$

where $D=\left[\operatorname{diag}\left(\sigma_{1}, \sigma_{2}, \ldots, \sigma_{a}\right) O\right]$ or $D=\left[\operatorname{diag}\left(\sigma_{1}, \sigma_{2}, \ldots\right.\right.$, $\left.\left.\sigma_{a}\right) O\right]^{\mathrm{T}}, O$ represents the zero matrix, and $a=\min (m, n)$, in which one of these two forms depends on the size of $m$ and $n$, where the diagonal elements satisfy the relation $\sigma_{1} \geq \sigma_{2} \geq, \ldots, \geq \sigma_{a} \geq 0$. The diagonal elements $\left(\sigma_{1}, \sigma_{2}, \ldots\right.$, $\left.\sigma_{a}\right)$ are referred to as singular values of matrix $X$.

We cannot obtain the complex transfer coefficients of the excitation points to the response points with data from a single stimulus test as in equation (1). Therefore, we usually select $n(n>1)$ excitation points during the test process, and set $m$ test steps during data processing. Then, we can obtain $m$-dimensional linear equations as given by equation the following equation (i.e., $m \geq n$ ):

$$
\left[\begin{array}{c}
P_{1} \\
P_{2} \\
\vdots \\
P_{j} \\
\vdots \\
P_{m}
\end{array}\right]=\left[\begin{array}{cccccc}
x_{o p 11} & x_{o p 12} & \ldots & x_{o p 1 i} & \ldots & x_{o p 1 n} \\
x_{o p 21} & x_{o p 22} & \ldots & x_{o p 2 i} & \ldots & x_{o p 2 n} \\
\vdots & \vdots & \ldots & \vdots & \ldots & \vdots \\
x_{o p j 1} & x_{o p j 2} & \ldots & x_{o p j i} & \ldots & x_{o p j n} \\
\vdots & \vdots & \ldots & \vdots & \ldots & \vdots \\
x_{o p m 1} & x_{o p m 2} & \ldots & x_{o p m i} & \ldots & x_{o p m n}
\end{array}\right] \cdot\left[\begin{array}{c}
h_{1} \\
h_{2} \\
\vdots \\
h_{i} \\
\vdots \\
h_{n}
\end{array}\right],
$$

where $P_{j}$ represents the target point response signal generated in the $j$ th test step, $h_{i}$ represents the transfer 
coefficient of the ith excitation point to the target point, and $x_{o p j i}$ represents the excitation signal at the $i$ th stimulus in the $j$ th test step.

Its matrix form can be simplified as follows:

$$
[P]=[X][H] .
$$

To solve the matrix $[H]$, we need to know the inversion of matrix $[X]$, which can be obtained from equation (2):

$$
\begin{gathered}
{[X]=[U][D][V]^{\mathrm{T}},} \\
{[X]^{-1}=[V][D]^{-1}[U]^{-1},}
\end{gathered}
$$

where $[U]$ is a positive definite matrix of $m \times m,[V]$ is a positive definite matrix of $n \times n$, and $[D]$ is a diagonal matrix of $m \times n$.

From equations (4) and (6), the transfer coefficient matrix $[H]$ can be calculated as shown in the following equation:

$$
[H]=[X]^{-1}[P] .
$$

During the test, the interference noise and crosstalk between measurement points are inevitable and will affect the accuracy of the transfer coefficient matrix $[H]$, resulting in a large deviation in the subsequent contribution results. To a certain extent, the PCA method can mitigate the effects of interference noise and the crosstalk phenomenon. The principal component analysis matrix $[T]$ is defined as shown in the following equation:

$$
[T]=[X][V]=[U][D] .
$$

In general, the larger elements of the diagonal matrix $[D]$ are considered to be the main component in the PCA progress, while the smaller elements are considered to be interference noise and crosstalk between excitation sources, which can be eliminated by zeroing out the smaller diagonal elements. After zero processing, we can obtain a new diagonal matrix $\left[D_{\mathrm{r}}\right]$ and the new positive definite matrixes $\left[U_{\mathrm{r}}\right]$ and $\left[V_{\mathrm{r}}\right]$. The new diagonal matrix $\left[D_{\mathrm{r}}\right]$ is expressed as shown in the following equation, where $r<a$ :

$$
\left[D_{\mathrm{r}}\right]=\left[\begin{array}{cccccc}
\sigma_{1} & & & & & \\
& \ddots & & & 0 & \\
& & \sigma_{\mathrm{r}} & & & \\
& 0 & & 0 & & \\
& & & & \ddots & \\
& & & & & 0
\end{array}\right] \text {. }
$$

The zero-processed PCA matrix is shown in the following equation:

$$
\left[T_{\mathrm{r}}\right]=[X]\left[V_{\mathrm{r}}\right]=\left[U_{\mathrm{r}}\right]\left[D_{\mathrm{r}}\right] .
$$

Equation (4) expresses the form of the main component analysis matrix multiplied by its coefficient matrix, as shown in the following equation:

$$
[P]=\left[T_{\mathrm{r}}\right][C] .
$$

The coefficient matrix $[C]$ is expressed as shown in the following equation:

$$
[C]=\left(\left[T_{\mathrm{r}}\right]^{\mathrm{T}}\left[T_{\mathrm{r}}\right]\right)^{-1}\left[T_{\mathrm{r}}\right]^{\mathrm{T}}[P] .
$$

Then, when the train runs at low speeds, the function matrix of the transfer coefficient of the structural radiated noise can be obtained as shown in the following equation:

$$
[H]=\left[V_{\mathrm{r}}\right][C]=\left[V_{\mathrm{r}}\right]\left[D_{\mathrm{r}}\right]^{-1}\left[U_{\mathrm{r}}\right][P] .
$$

Since the transfer coefficient function of structural radiated noise does not vary with the speed, the transfer coefficient function of the structural radiated noise obtained at low speeds is used for the high-speed scenario. According to the high-speed excitation source signal matrix and lowspeed transfer function matrix, the contribution of the structural radiated noise to the target response point at high speed, $p_{i}$, and the total structural noise contribution, $P_{\mathrm{st}}$, can be solved as shown in the following equations:

$$
\begin{aligned}
x_{o p i} * h_{i} & =p_{i}, \\
P_{\mathrm{st}} & =\sum_{i=1}^{n} p_{i} .
\end{aligned}
$$

2.2. Aerodynamic Noise Separation Based on Wave Superposition. $P_{\text {est }}$ is the effective value of the structural radiated noise, $P_{\mathrm{st}}$, at high speed. $P_{\mathrm{ea}}$ is the effective value of the aerodynamic noise, $P_{\mathrm{a}} \cdot P_{\mathrm{eT}}$ is the effective value of the target noise point total noise, $P_{\mathrm{T}}$. Because the structural radiated noise is not related to the aerodynamic noise, the following equation can be obtained according to the wave superposition principle:

$$
P_{\mathrm{eT}}^{2}=P_{\mathrm{ea}}^{2}+P_{\mathrm{est}}^{2} .
$$

Then, the following equation is obtained:

$$
L_{P_{\mathrm{T}}}=10 \log \left(10^{0.1 L_{P_{\mathrm{a}}}}+10^{0.1 L_{P_{\mathrm{st}}}}\right) \text {, }
$$

where $L_{P_{\mathrm{T}}}$ is the sound pressure level of the target response point total noise, $P_{\mathrm{T}} ; L_{P_{\mathrm{a}}}$ is the sound pressure level of the target response point aerodynamic noise, $P_{\mathrm{a}}$; and $L_{P_{\mathrm{st}}}$ is the sound pressure level of the target response point's structural radiated noise, $P_{\mathrm{st}}$.

The aerodynamic noise is separated from the target response point total noise, $L_{P_{\mathrm{T}}}$, as shown in

$$
L_{P_{\mathrm{a}}}=10 \log \left(10^{0.1 L_{P_{\mathrm{T}}}}-10^{0.1 L_{P_{\mathrm{st}}}}\right) \text {, }
$$

where $L_{P_{\mathrm{T}}}$ is obtained directly from the test and $L_{P_{\mathrm{st}}}$ is the structural radiated noise at the target response point obtained from the analysis of the transfer path.

3. EMU Noise Separation Test Scheme and Measuring Point Layout. The test object is the middle trailer of a high-speed EMU. The test circuit is an overhead line with no reflector around it. During the test, the train first performs a low- 
speed idle running test at a speed of $5 \mathrm{~km} / \mathrm{h}$. Then, the OTPA technique is used on the measured data to obtain the transfer coefficient function of the structural radiated noise. The running test is performed in the train at 200,250,300, and $350 \mathrm{~km} / \mathrm{h}$. The test site is shown in Figure 1.

The sensor placement and measurement point description are shown in Figure 2 and Table 1, respectively, where Figure 2(a) is a top view of the measuring point arrangement and Figure 2(b) is a side view of the measuring point arrangement.

To reduce the impact of aerodynamic noise on the test, the wheel-rail noise test microphones are installed in the groove at a lower position closest to the wheel-rail contact point and points towards the wheel. For the wheel-rail contact point, the linear velocity is zero when the train is running, so the aerodynamic noise generated by the wheelrail at this position is almost zero. The intensity of the acoustic radiation of the wheel gradually increased with the increase of the running speed of the train, but the directivity of the main mode radiation noise of the wheel and the position of the sound source did not change significantly, which can ensure the accuracy of the transfer path analysis under different speed grades [20].

A kind of gun microphone that convinces with its excellent directivity was used to reduce the influence of wind noise and aerodynamic noise from other directions. The microphone's polar diagram is shown in Figure 3.

The microphone's filter module effectively filters out interference caused by infrasound, such as low-frequency wind noise. The microphone is also equipped with a foam windshield. The windshield changes the sound only slightly but attenuates wind noise by approx. $25 \mathrm{~dB}$. As shown in Figure 4, place the foam windshield (1) over the microphone head (2) so that all lateral slots are covered.

Figure 5 shows the site layout of a portion of the measuring points, where Figure 5(a) is an air spring bogie frame measuring point and Figure 5(b) is the axle box-bogie frame measuring point.

According to the measuring points in Figure 2 and Table 1, the transfer path analysis network of the high-speed train bogie is established, as shown in Figure 6, and the contribution of the structural radiated noise of the bogie area in each speed level is obtained. A comparison of the OTPA composite value of the response point with the test value of the response point at each speed level illustrates that the aerodynamic contribution at high speeds can be separated based on the sound pressure level superposition from equation (17).

\section{Analysis of the Aerodynamic Noise Separation Test Results of EMU Trains}

4.1. Vibration and Noise Characteristics of the Main Measuring Points. Before analysing the vibration and noise transfer paths and separating the aerodynamic noise, a preliminary analysis of the test data was conducted. Figure 7 shows the wheel-rail noise of the 4th position and the response point bogie area noise at each speed.

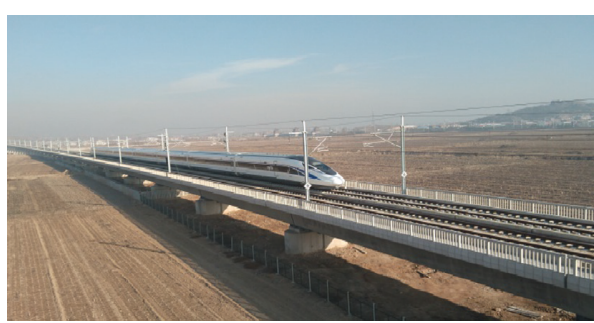

Figure 1: Test site.

As shown in Figure 7, the noise at the two measurement points is mainly concentrated in the frequency range between $100 \mathrm{~Hz}$ and $5,000 \mathrm{~Hz}$ at each speed. The total values of the bogie area noise in the overall analysis frequency band at $5,200,250,300$, and $350 \mathrm{~km} / \mathrm{h}$ are $64.2,111.4,113.8,118.7$, and $122.1 \mathrm{~dB}(\mathrm{~A})$, respectively. The total values of the wheelrail noise of the 4th position in the overall analysis frequency band at $5,200,250,300$, and $350 \mathrm{~km} / \mathrm{h}$ are $66.9,113.4,115.8$, 118.7 , and $121.4 \mathrm{~dB}(\mathrm{~A})$, respectively. As the speed increases, the noise amplitude of each measuring point also shows an increasing trend, and the measured signal is in agreement with the known rate of change.

Figure 8 shows the FFT spectrum of the $Z$-axis of the axle box-bogie frame at the four positions at each speed. The metal plate of the bogie frame has large thickness, and the vibration excited by aerodynamic force can be neglected.

As shown in Figure 8, the vibration at the $Z$-axis vibration measurement point of the axle box-bogie frame at a speed of $5 \mathrm{~km} / \mathrm{h}$ is mainly concentrated in the frequency band below $300 \mathrm{~Hz}$. The total values of the vibration of axle box-bogie frames 1 to 4 in the analysis frequency band are $0.24,0.24,0.23$, and $0.22 \mathrm{~m} / \mathrm{s}^{2}$, respectively. At speeds of 200 , 250,300 , and $350 \mathrm{~km} / \mathrm{h}$, the vibration at the $Z$-axis vibration measurement point of the axle box-bogie frame is mainly concentrated in the frequency band below $1,000 \mathrm{~Hz}$. At $200 \mathrm{~km} / \mathrm{h}$, the total values of vibration of axle box-bogie frames 1 to 4 in the analysis frequency band are 4.21, 4.25, 4.17 , and $3.54 \mathrm{~m} / \mathrm{s}^{2}$, respectively. At $250 \mathrm{~km} / \mathrm{h}$, the total values of vibration are $5.24,5.24,5.49$, and $4.97 \mathrm{~m} / \mathrm{s}^{2}$, respectively. At $300 \mathrm{~km} / \mathrm{h}$, the total values of vibration are 7.04 , $6.91,7.04$, and $6.94 \mathrm{~m} / \mathrm{s}^{2}$, respectively. At $350 \mathrm{~km} / \mathrm{h}$, the total values of vibration are $7.74,7.73,8.07$, and $7.79 \mathrm{~m} / \mathrm{s}^{2}$, respectively. As the speed increases, the total value of vibration of axle box-bogie frames 1 to 4 in the analysis frequency band shows an increasing trend.

4.2. Analysis of the Aerodynamic Noise Separation Results. According to the theory in Part 2 and the TPS calculation network in Figure 6, the structural radiated noise is analysed and calculated, and the aerodynamic noise is extracted. The aerodynamic noise generated by the train operation is very small under low-speed $(0-5 \mathrm{~km} / \mathrm{h})$ operation, and the effect of aerodynamic noise on the total noise of the bogie area can be ignored. Using the measured vibration and noise data, such as the data for the wheel-rail and bogie frame, the transfer coefficient function of the wheel-rail noise to the central area of the bogie and the vibration of the bogie frame 


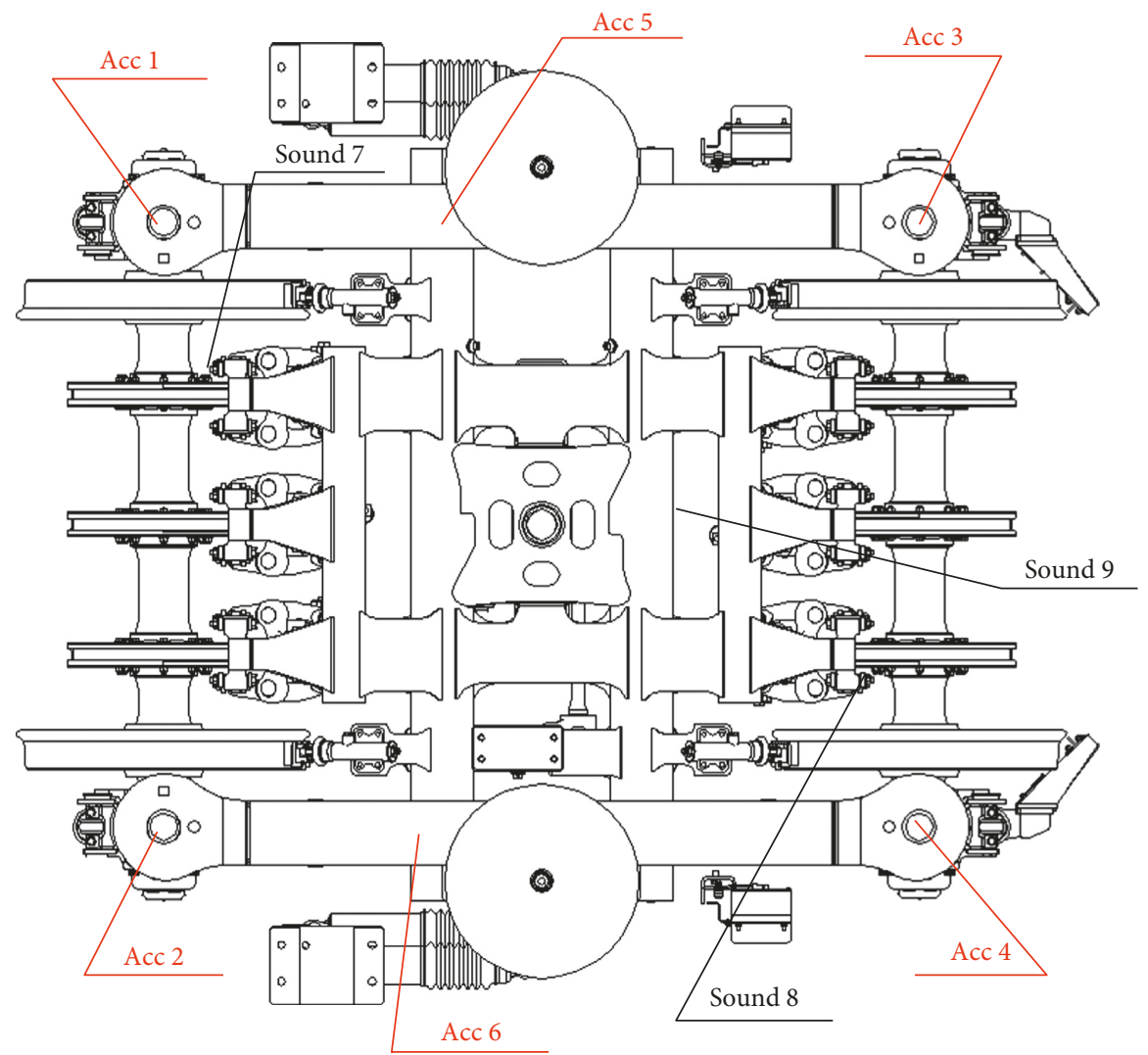

(a)

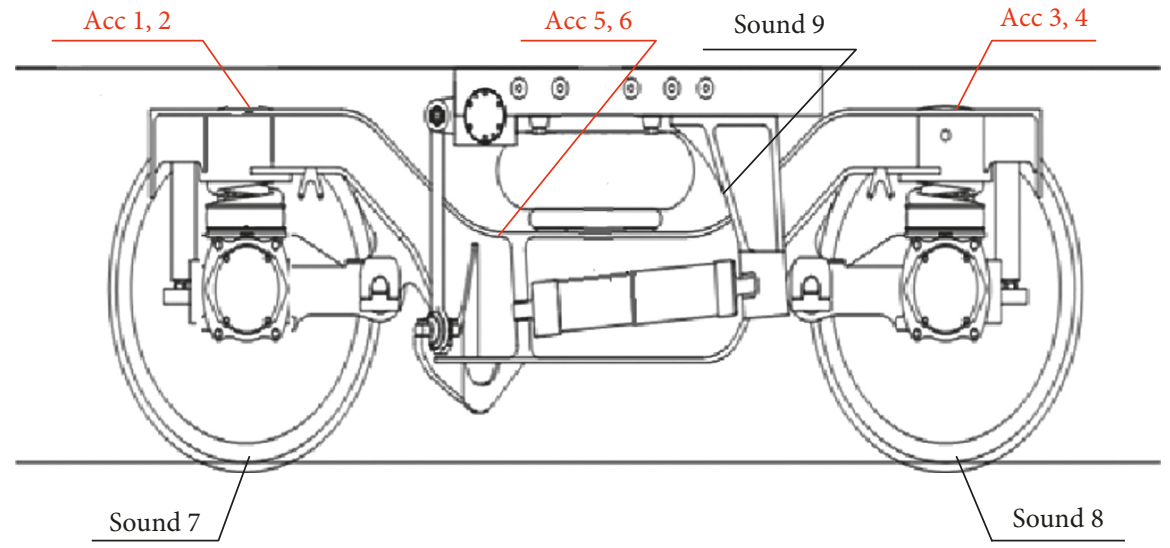

(b)

FIgURE 2: Measuring point layout. (a) Top view. (b) Side view.

to the central area of the bogie is obtained. The transfer coefficient function is used for the structural radiated noise analysis of trains operating at high speeds. In the TPS calculation network of Figure 6, the source signal is the test signal from the bogie area structure under high-speed running conditions of the train, and the transfer coefficient function is obtained when the train is running at speeds of $0-5 \mathrm{~km} / \mathrm{h}$. Figure 9 shows a spectrum diagram of actual test noise and the structural radiated noise at the target response point, calculated from the TPS network.

As shown in Figure 9, there is a clear difference between the structure radiation noise and measured noise spectra at each speed. The spectra of structural radiated noise and test noise in the lower-frequency section are in good agreement, indicating that the structural radiated noise of the bogie area is dominant in this frequency band. The difference between the test noise and structural radiated noise in the highfrequency region is significant, mainly due to the enhanced aerodynamic noise effect in this frequency band. The total noise in the analysis frequency band at the test response point of $200 \mathrm{~km} / \mathrm{h}$ is $111.5 \mathrm{~dB}(\mathrm{~A})$, and the total value of the structural radiated noise obtained from the transfer path analysis is $109.3 \mathrm{~dB}(\mathrm{~A})$. The total noise in the analysis frequency band at the test response point of $250 \mathrm{~km} / \mathrm{h}$ is 
TABLE 1: Location and description of the measuring points.

\begin{tabular}{|c|c|c|c|}
\hline & Measuring point & Sensor type & Measuring point description \\
\hline 1 & Axle box-bogie frame vibration 1 & Acceleration & $\begin{array}{c}\text { Measuring the vibration of the 1st position axle box to } \\
\text { the frame }\end{array}$ \\
\hline 2 & Axle box-bogie frame vibration 2 & Acceleration & $\begin{array}{c}\text { Measuring the vibration of the } 2 \text { nd position axle box } \\
\text { to the frame }\end{array}$ \\
\hline 3 & Axle box-bogie frame vibration 3 & Acceleration & $\begin{array}{l}\text { Measuring the vibration of the } 3 \text { rd position axle box } \\
\text { to the frame }\end{array}$ \\
\hline 4 & Axle box-bogie frame vibration 4 & Acceleration & $\begin{array}{l}\text { Measuring the vibration of the } 4 \text { th position axle box } \\
\text { to the frame }\end{array}$ \\
\hline 5 & Air spring bogie frame vibration 1 & Acceleration & $\begin{array}{l}\text { Measuring the vibration of the 1st position air spring } \\
\text { to the frame }\end{array}$ \\
\hline 6 & Air spring bogie frame vibration 2 & Acceleration & $\begin{array}{l}\text { Measuring the vibration of the } 2 \text { nd position air spring } \\
\text { to the frame }\end{array}$ \\
\hline 7 & Wheel-rail noise 1 & Sound & $\begin{array}{l}\text { Installed in the groove close to the wheel-rail contact } \\
\text { point and points to the wheel to measure the wheel- } \\
\text { rail noise of the 1st position }\end{array}$ \\
\hline 8 & Wheel-rail noise 4 & Sound & $\begin{array}{l}\text { Installed in the groove close to the wheel-rail contact } \\
\text { point and points to the wheel to measure the wheel- } \\
\text { rail noise of the } 4 \text { th position }\end{array}$ \\
\hline 9 & Bogie area noise & Sound & Measurement of the bogie area noise \\
\hline
\end{tabular}

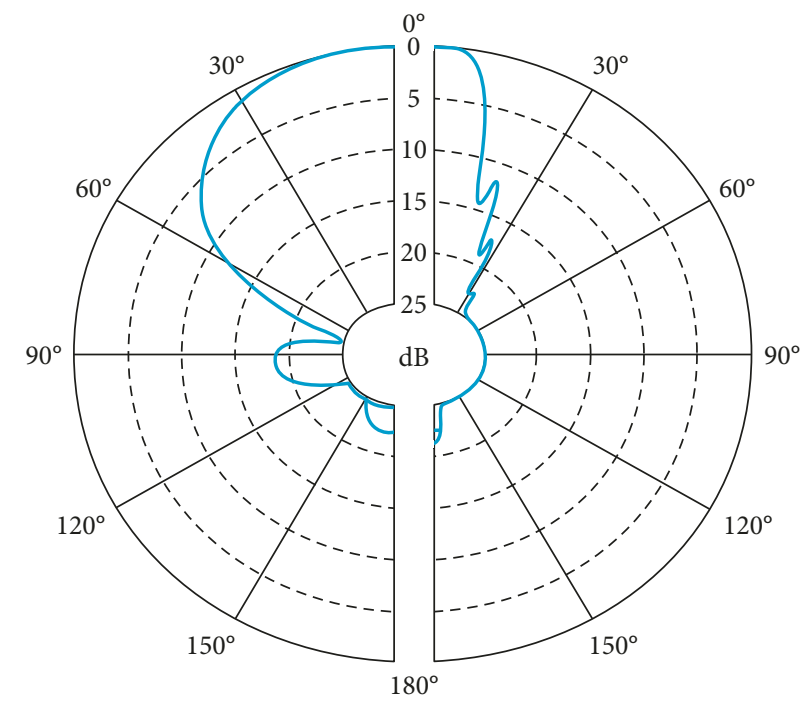

$1000 \mathrm{~Hz}$

Figure 3: Microphone's polar diagram.

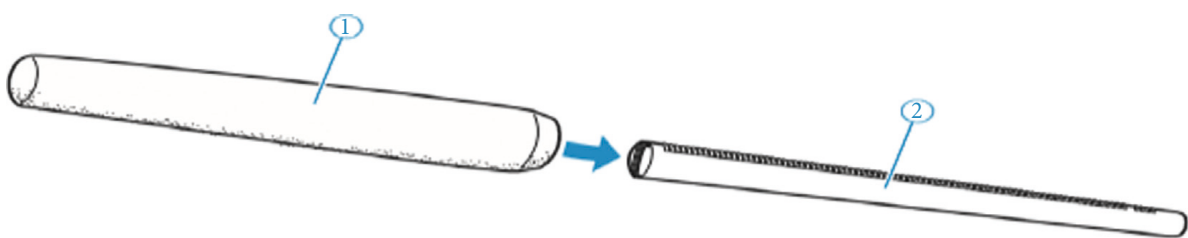

FIGURE 4: Microphone's windshield.

$113.9 \mathrm{~dB}(\mathrm{~A})$, and the total value of the structural radiated noise obtained from the transfer path analysis is $110.9 \mathrm{~dB}(\mathrm{~A})$. The total noise in the analysis frequency band at the test response point of $300 \mathrm{~km} / \mathrm{h}$ is $118.8 \mathrm{~dB}(\mathrm{~A})$, and the total value of the structural radiated noise obtained from the transfer path analysis is $115.7 \mathrm{~dB}(\mathrm{~A})$. The total noise in the analysis frequency band at the test response point of $350 \mathrm{~km} /$ $\mathrm{h}$ is $122.3 \mathrm{~dB}(\mathrm{~A})$, and the total value of the structural radiated noise obtained from the transfer path analysis is $118.2 \mathrm{~dB}(\mathrm{~A})$. 


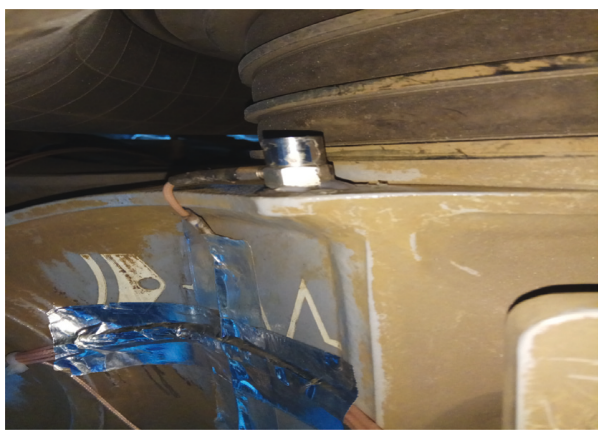

(a)

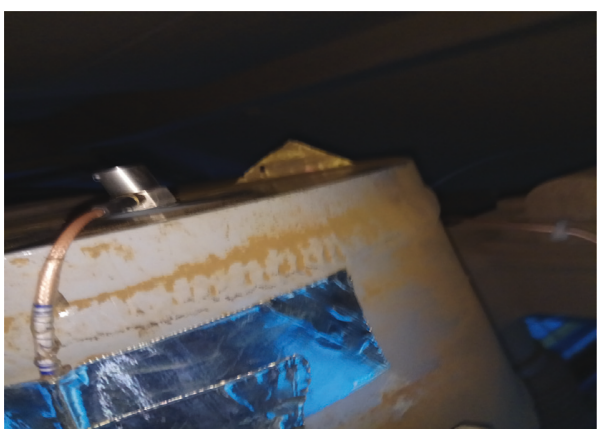

(b)

Figure 5: Site layout of a portion of the measuring points. (a) Air spring bogie frame. (b) Axle box-bogie frame.

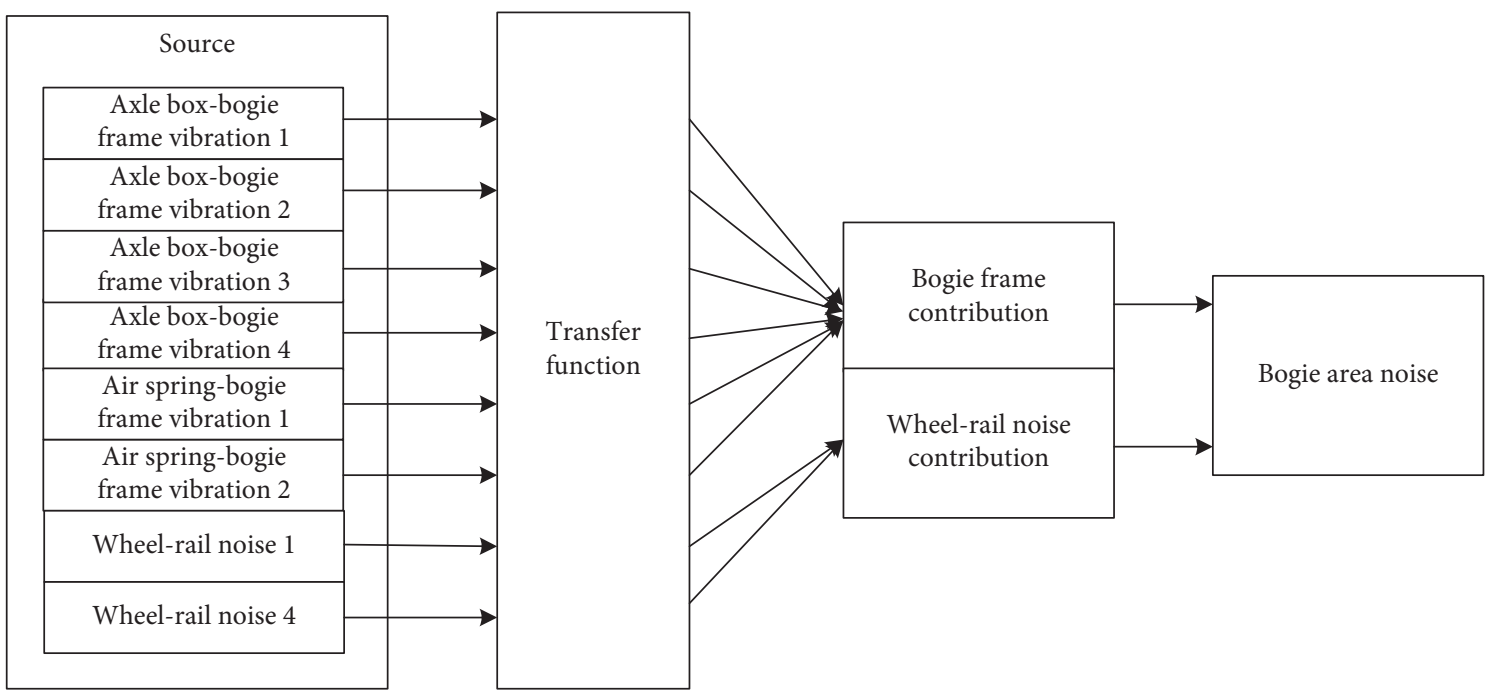

FIGURE 6: Bogie area transfer path TPS computing network.

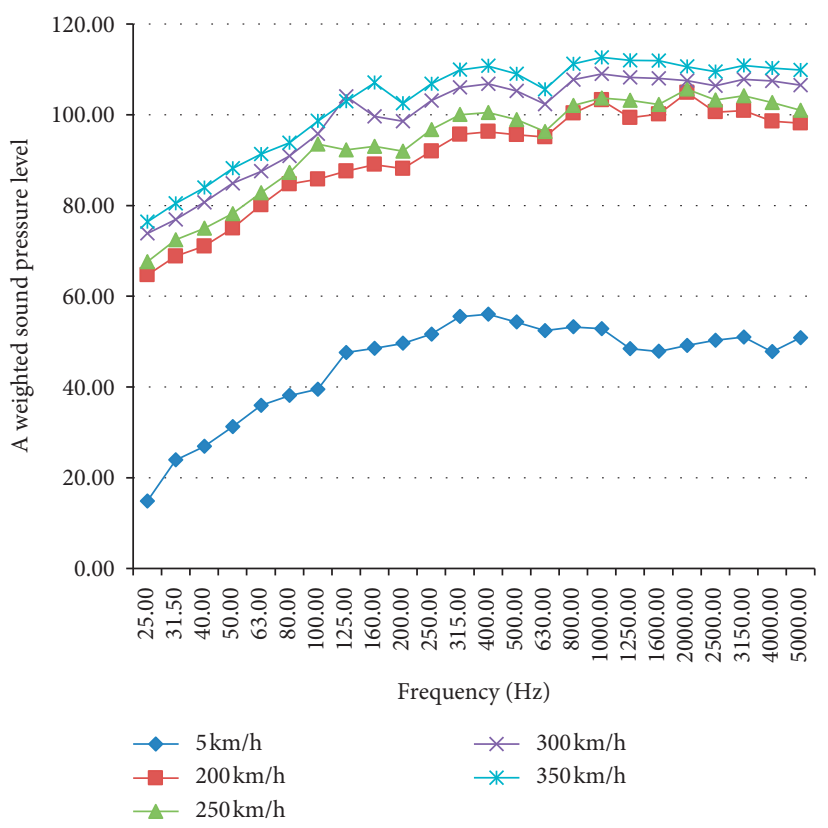

(a)

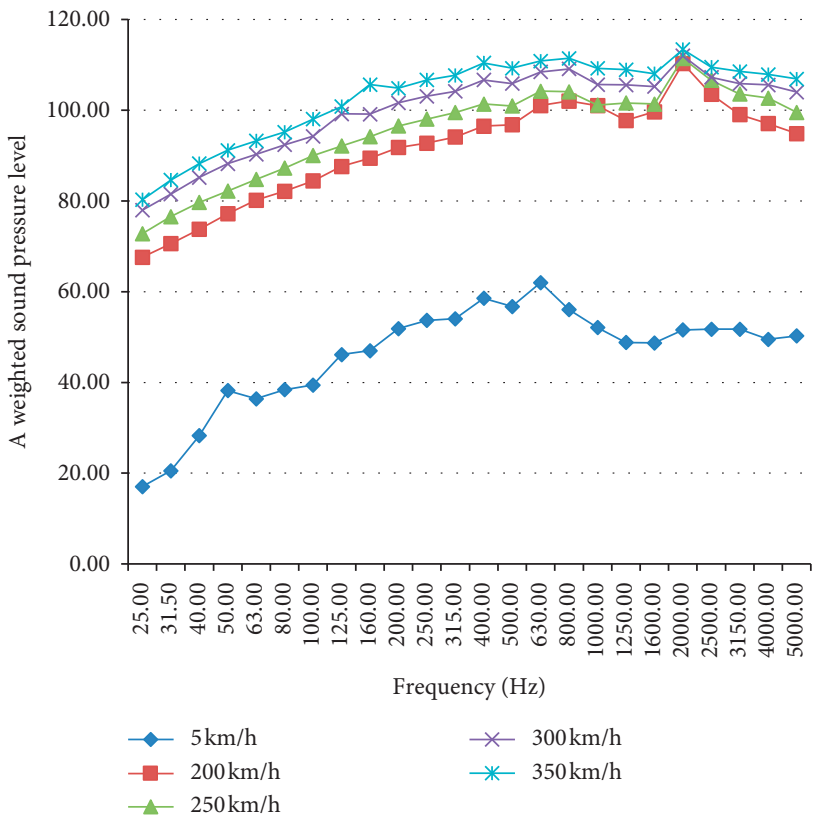

(b)

Figure 7: Noise sources at each speed. (a) Bogie area noise. (b) Wheel-rail noise of the 4th position. 


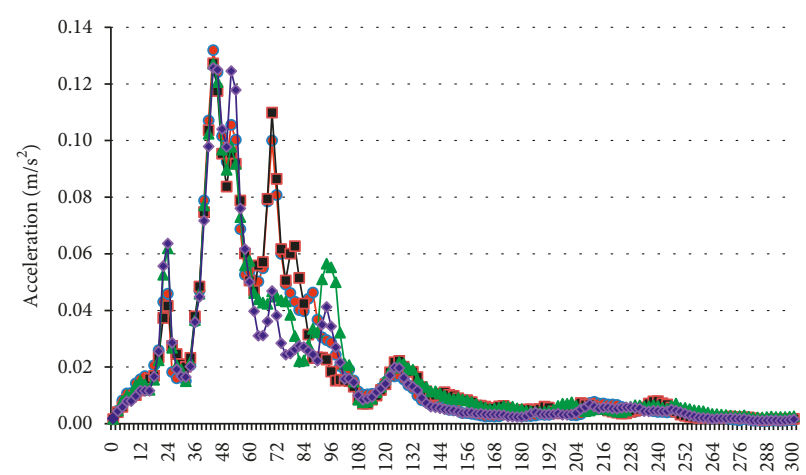

Frequency $(\mathrm{Hz})$

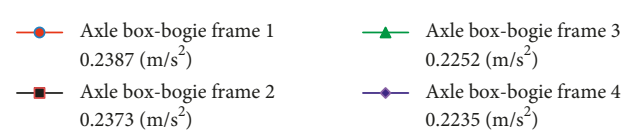

(a)

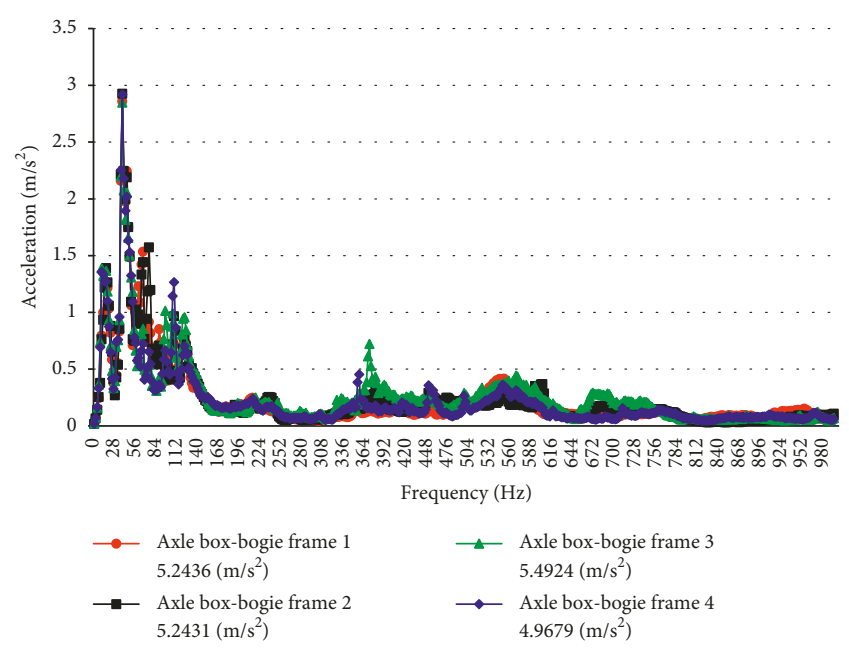

(c)

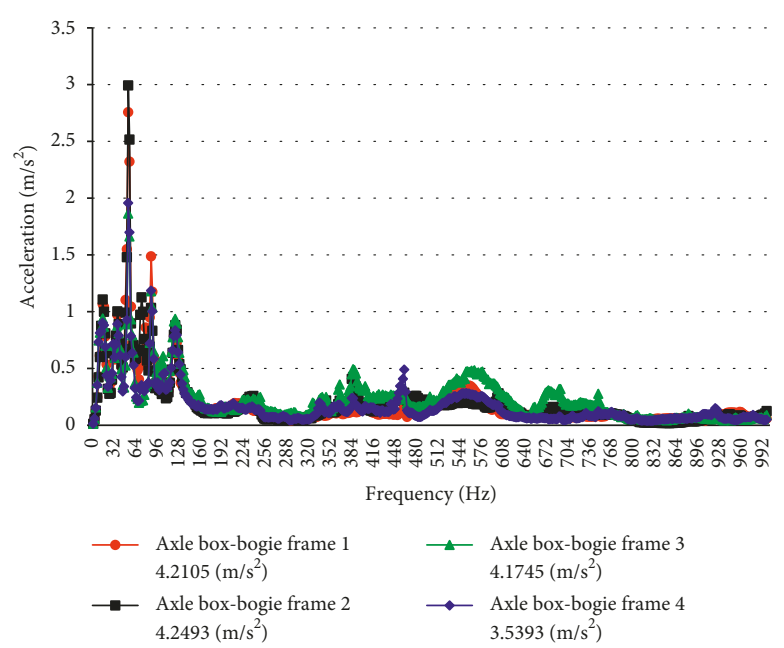

(b)

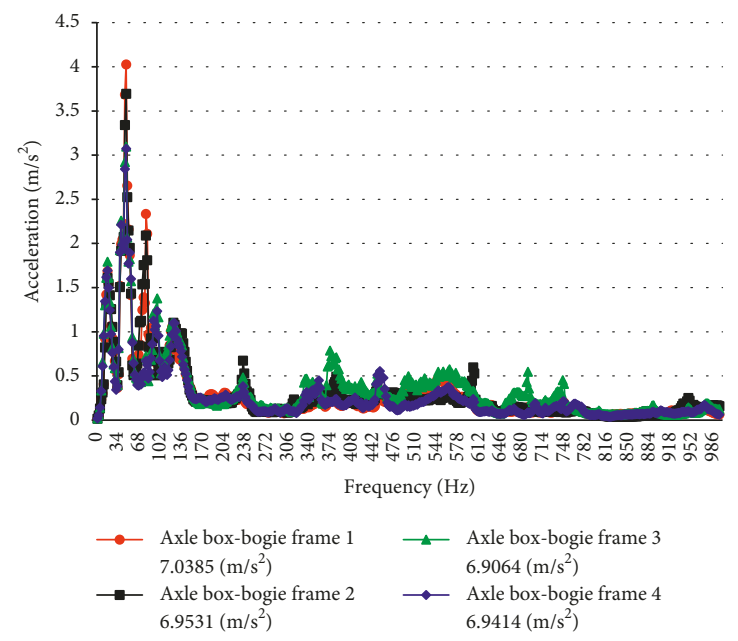

(d)

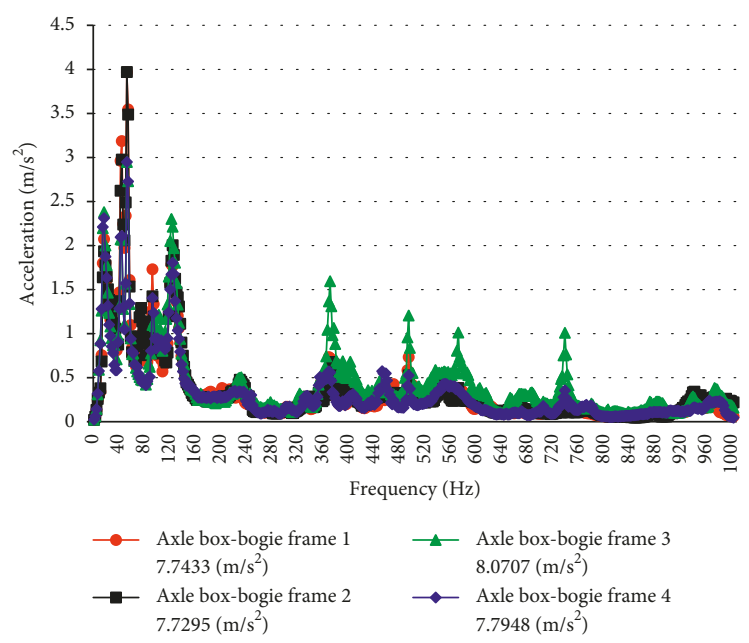

(e)

FIGURE 8: FFT spectrum of the Z-axis of the axle box-bogie frame at each speed. (a) $5 \mathrm{~km} / \mathrm{h}$. (b) $200 \mathrm{~km} / \mathrm{h}$. (c) $250 \mathrm{~km} / \mathrm{h}$. (d) $300 \mathrm{~km} / \mathrm{h}$. (e) $350 \mathrm{~km} / \mathrm{h}$. 


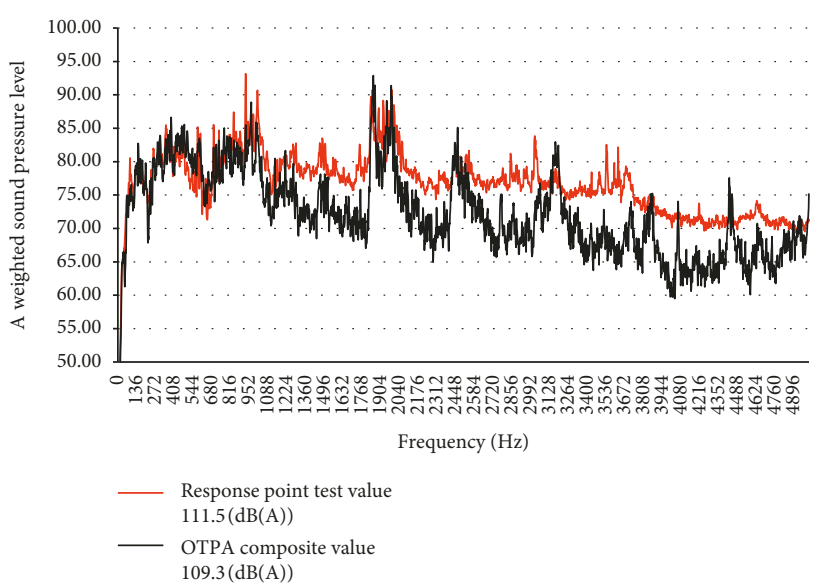

(a)

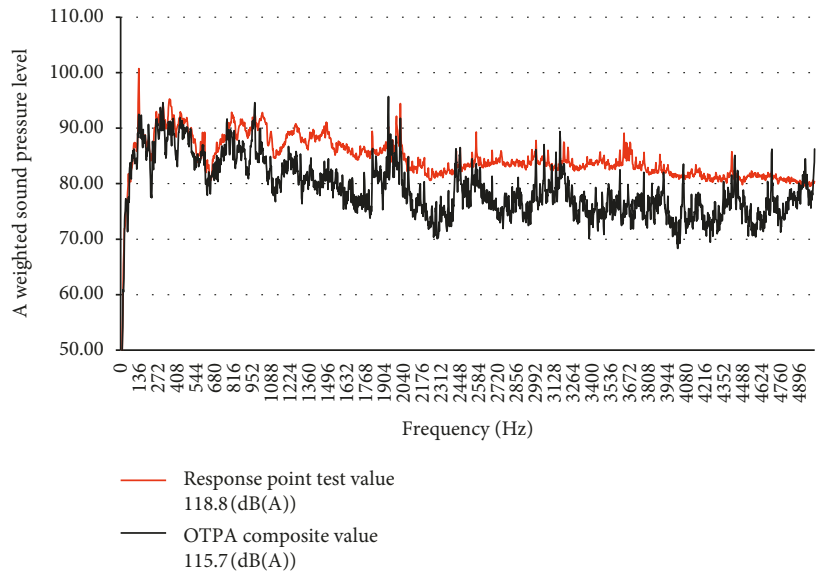

(c)

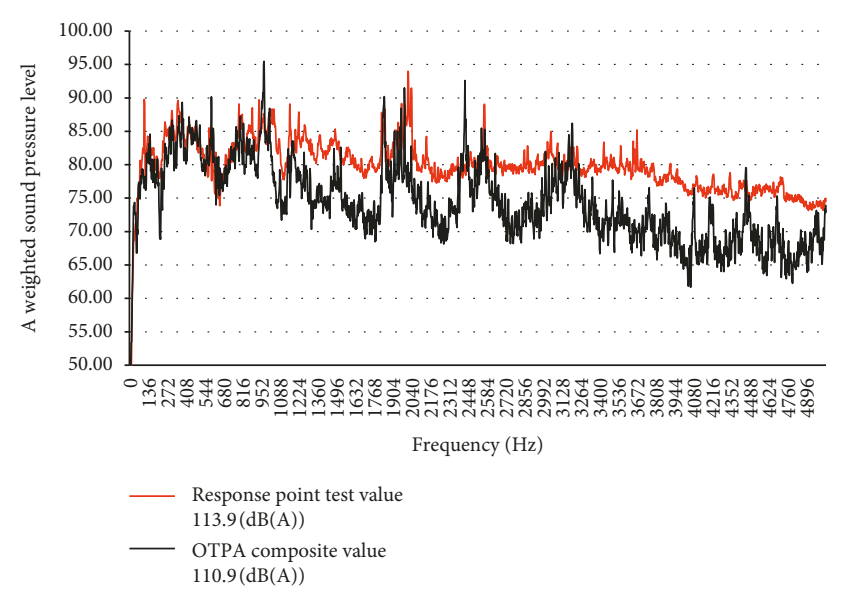

(b)

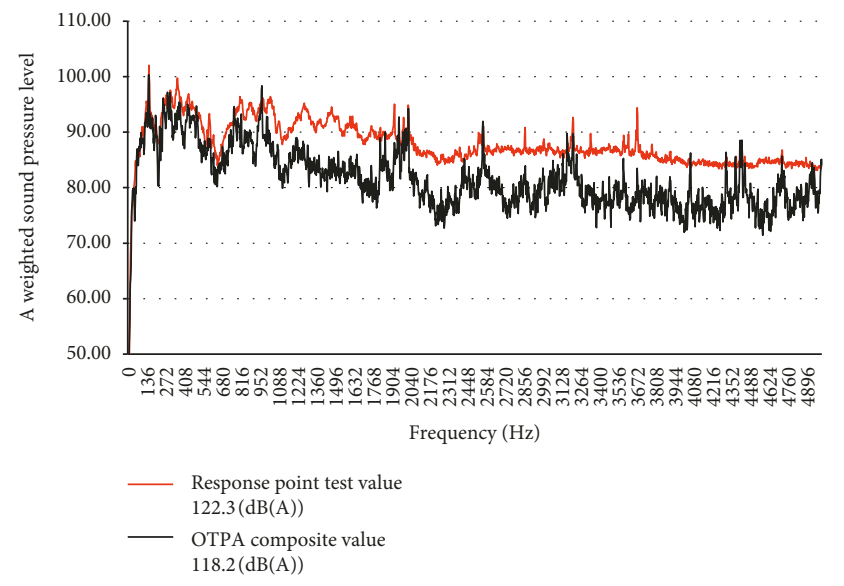

(d)

FIGURE 9: Spectrum diagram of the actual test noise and structural radiated noise at the target response point. (a) $200 \mathrm{~km} / \mathrm{h}$. (b) $250 \mathrm{~km} / \mathrm{h}$. (c) $300 \mathrm{~km} / \mathrm{h}$. (d) $350 \mathrm{~km} / \mathrm{h}$.

The contribution of aerodynamic noise at each speed can be separated according to equation (17). The bogie area aerodynamic noise separation results are shown in Figure 10.

Figure 10 illustrates that the structural radiated noise and aerodynamic noise increase with increasing speed. The contribution of aerodynamic noise is highly similar to that of structural radiated noise at a speed of $250 \mathrm{~km} / \mathrm{h}$, and the contribution of structural radiated noise is higher than that of aerodynamic noise at velocities below $250 \mathrm{~km} / \mathrm{h}$. When the speed is higher than $250 \mathrm{~km} / \mathrm{h}$, the aerodynamic noise contribution to the response point of the bogie area is higher than that of the structural radiated noise. As the speed increases, the difference between the aerodynamic noise and structural radiated noise increases.

\section{Conclusions}

In this paper, the separation of aerodynamic noise in a highspeed train trailer bogie area is studied. Since there is low aerodynamic noise when the train is running at low speeds, the transfer coefficient function calculated at low speeds is substituted into the calculation of the transfer path contribution of the high-speed structure, and then, the

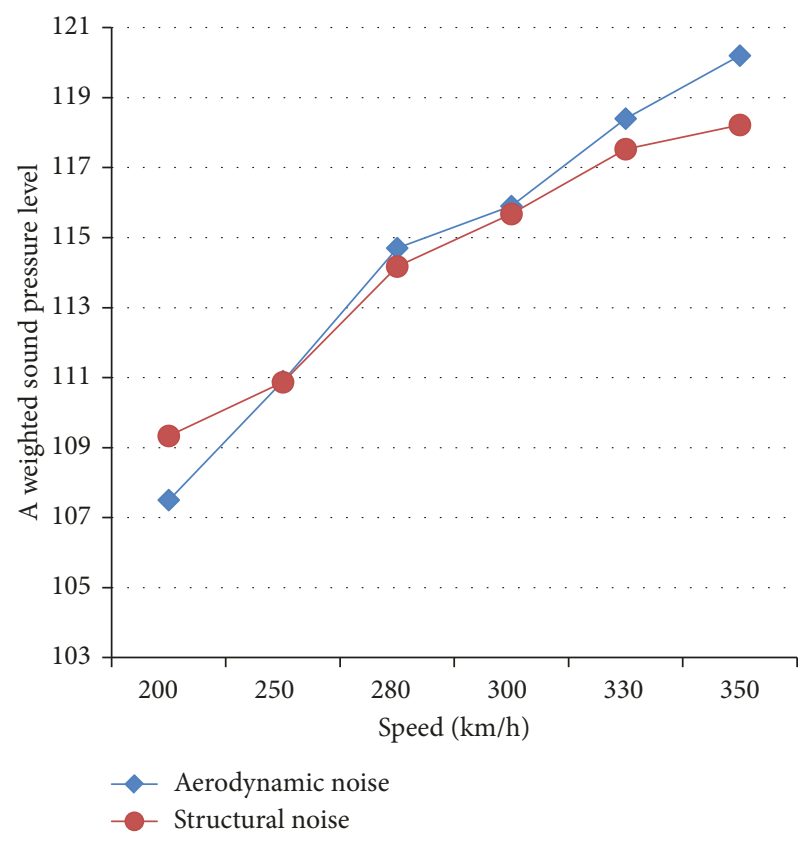

FIGURE 10: Structure radiated noise and aerodynamic noise contribution at each speed. 
aerodynamic noise in the bogie region is separated at high speeds. The noise contribution of the aerodynamic noise to the target response point can then be obtained. The following conclusions can be drawn:

1. In the central area of the middle trailer bogie of highspeed trains, the low-frequency noise mainly comes from the structural radiated noise of the bogie, and the mid- to high-frequency noise is primarily due to aerodynamic noise.

2. Analysis of test data shows that when an EMU train operates at speeds below $250 \mathrm{~km} / \mathrm{h}$, the noise in the central area of the middle trailer bogie is primarily caused by the structural radiated noise. When the operating speed is higher than $250 \mathrm{~km} / \mathrm{h}$, the noise in the central area of the middle trailer bogie is mainly due to aerodynamic noise, and the aerodynamic noise contribution increases with increasing speed.

\section{Data Availability}

The data used to support the findings of this study are available from the corresponding author upon request.

\section{Conflicts of Interest}

The authors declare that there are no conflicts of interest regarding the publication of this paper.

\section{Acknowledgments}

This work was financially supported by the China Railway Science and Technology Research and Development Project (2015z003 and SY2016Z001).

\section{References}

[1] D. J. Thompson, E. Latorre Iglesias, X. Liu et al., "Recent developments in the prediction and control of aerodynamic noise from high-speed trains," International Journal of Rail Transportation, vol. 3, no. 3, pp. 119-150, 2015.

[2] E. Latorre Iglesias, D. J. Thompson, and M. G. Smith, "Component-based model to predict aerodynamic noise from high-speed train pantographs," Journal of Sound and Vibration, vol. 394, pp. 280-305, 2017.

[3] Y. Zhang, J. Zhang, T. Li, and L. Zhang, "Investigation of the aeroacoustic behavior and aerodynamic noise of a high-speed train pantograph," Science China Technological Sciences, vol. 60, no. 4, pp. 561-575, 2017.

[4] Y. Gao, Y. G. Wang, and J. T. Wang, "Testing study of aerodynamic noise for high-speed train model in aeroacoustic wind tunnel," Tech. Rep., Technical Acoustic, Loughborough, UK, 2013.

[5] G. Han, J. Zhang, X. Xiao et al., "Study on high speed train abnormal interior vibration and noise related to wheel roughness," Journal of Mechanical Engineering, vol. 50, no. 22, pp. 113-121, 2014.

[6] X. Q. Sun, H. Xiao, and C. Z. Wu, "Numerical modeling and investigation on aerodynamic noise characteristics of pantographs in high-speed trains," Complexity, vol. 2018, article 6932596, 12 pages, 2018.
[7] J. Y. Zhu, Z. W. Hu, and D. J. Thompson, "Flow behavior and aeroacoustics characteristics of a simplified high-speed train bogie," Proceedings of Institution of Mechanical Engineers, Part F: Journal of Rail and Rapid Transit, vol. 230, no. 7, pp. 1642-1658, 2015.

[8] H. Li, X. B. Xiao, and X. S. Jin, "Investigation into aerodynamic noise characteristics of train head car bogie based on simplified models," Journal of Mechanical Engineering, vol. 52, no. 8, pp. 152-161, 2016.

[9] J. Lan and J. Han, "Research on the radiated characteristics of aerodynamic noises of a simplified bogie of the high-speed train," Journal of Vibroengineering, vol. 19, no. 3, pp. 22802293, 2017.

[10] J. Y. Zhu, Z. W. Hu, and D. J. Thompson, "The flow and flowinduced noise behavior of a simplified high-speed train bogie in the cavity with and without a fairing," Proceedings of Institution of Mechanical Engineers, Part F: Journal of Rail and Rapid Transit, vol. 232, no. 3, pp. 759-773, 2018.

[11] Y. Nobuhiro and I. Atsushi, "Evaluation methods for aerodynamic noise from a high-speed train bogie in a wind tunnel test," Inter-Noise, vol. 11, no. 11, pp. 1403-2172, 2011.

[12] E. Latorre Iglesias, D. J. Thompson, M. Smith et al., "Anechoic wind tunnel tests on high speed train bogie aerodynamic noise," International Journal of Rail Transportation, vol. 5, no. 2, pp. 87-109, 2017.

[13] J. Y. Zhu, Z. W. Hu, and D. J. Thompson, "Flow simulation and aerodynamic noise prediction for a high-speed train wheelset," International Journal of Aeroacoustics, vol. 13, no. 7, pp. 533-552, 2014.

[14] S. Huang, M. Z. Yang, Z. W. Li et al., "Aerodynamic noise numerical simulation and noise reduction of high-speed train bogie section," Journal of Central South University (Science and Technology), vol. 42, no. 12, pp. 3899-3904, 2011.

[15] Y. D. Zhang, J. Y. Zhang, L. Zhang et al., "Numerical analysis of aerodynamic noise of motor car bogie for high-speed trains," Journal of Southwest Jiaotong University, vol. 51, no. 5, pp. 70-877, 2016.

[16] Y. D. Zhang, J. Y. Zhang, T. Li et al., "Numerical research on aerodynamic noise of trailer bogie," Journal of Mechanical Engineering, vol. 52, no. 16, pp. 106-116, 2016.

[17] K. Morita, S. Masaaki, K. Shigeru et al., "Numerical analysis of aerodynamic sound sources around bogie section of high speed train," Turkish Acoustical Society-36th International Congress and Exhibition on Noise Control Engineering, InterNoise 2007 Istanbul, vol. 1, pp. 906-1783, 2007.

[18] N. Frémion, N. Vincent, M. Jacob, G. Robert, A. Louisot, and S. Guerrand, "Aerodynamic noise radiated by the inter coach spacing and the bogie of a high-speed train," Journal of Sound and Vibration, vol. 231, no. 3, pp. 577-593, 2000.

[19] D. de Klerk and A. Ossipov, "Operational transfer path analysis: theory, guidelines and tire noise application," $M e$ chanical Systems and Signal Processing, vol. 24, no. 7, pp. 1950-1962, 2010.

[20] J. Y. Fang, X. B. Xiao, X. S. Jin et al., "Effect of train speed on acoustic radiation characteristics of high-speed train wheel vibration," Journal of Mechanical Engineering, vol. 46, no. 22, pp. 96-104, 2010. 


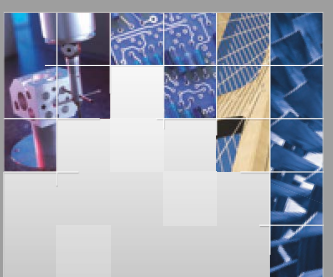

\section{Enfincering}
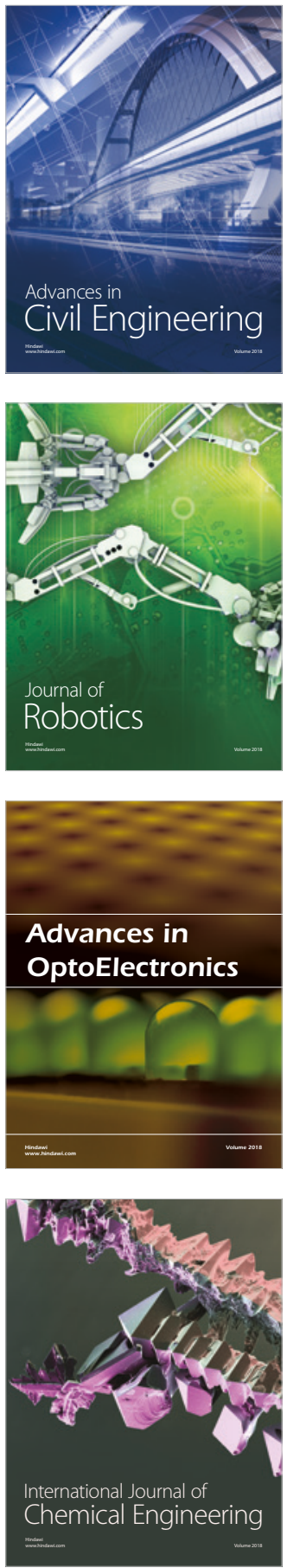

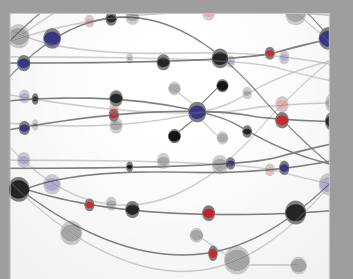

\section{Rotating \\ Machinery}

The Scientific World Journal

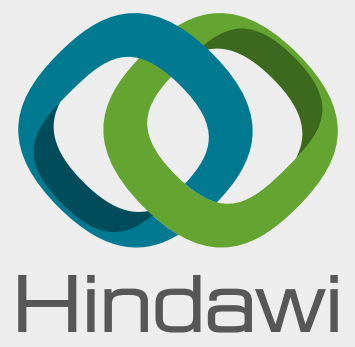

Submit your manuscripts at

www.hindawi.com
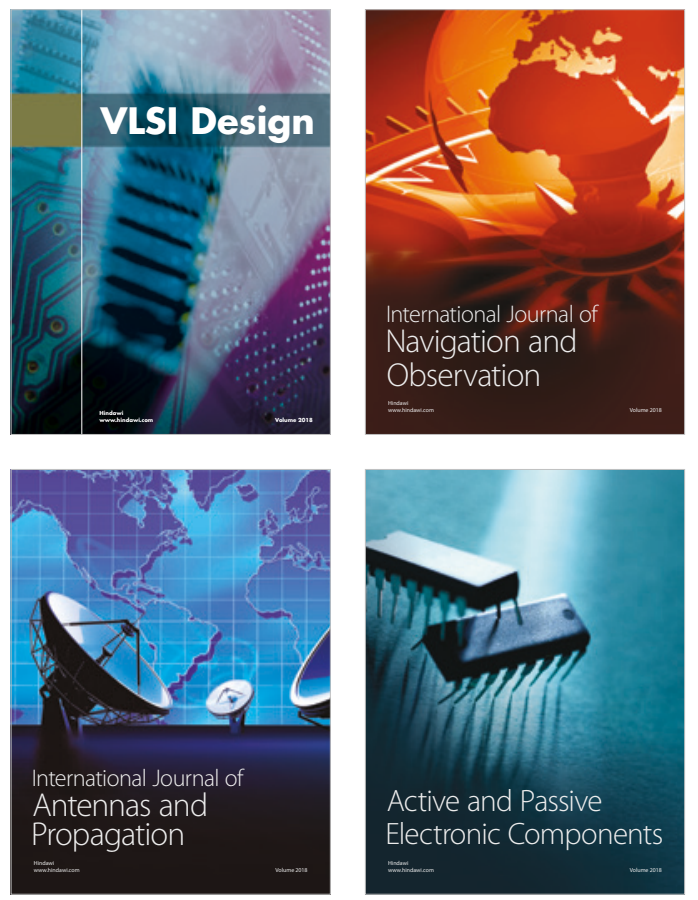
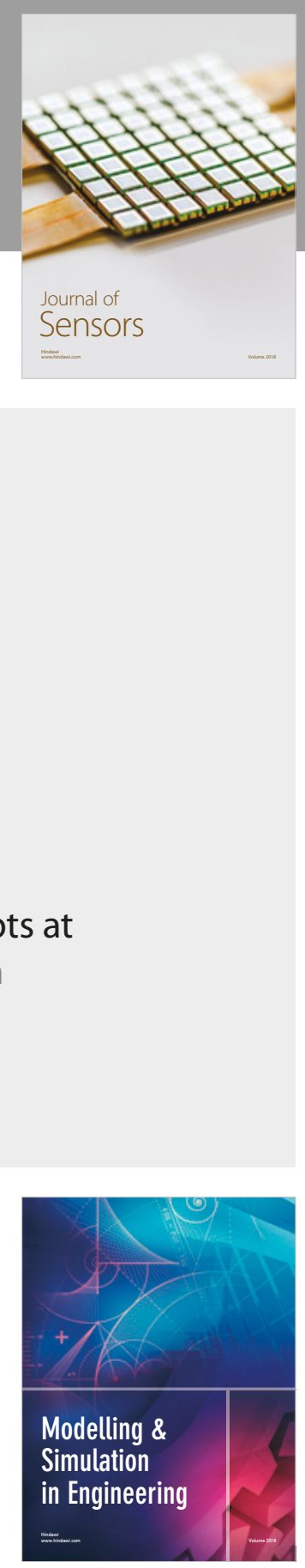

\section{Advances \\ Multimedia}
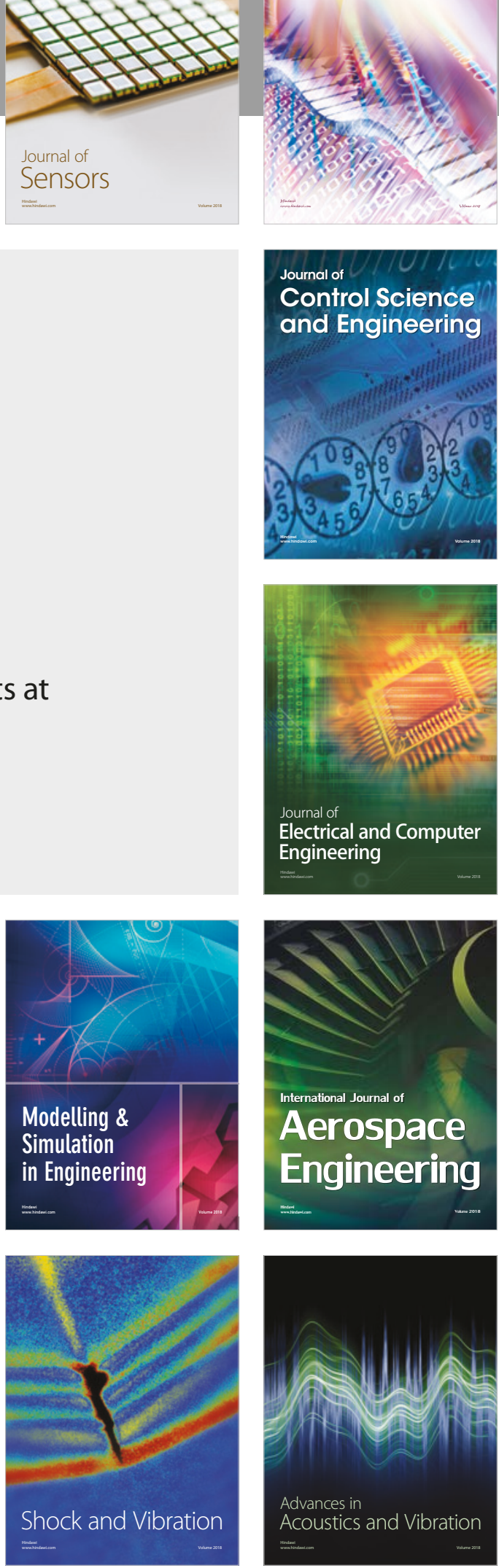